\title{
Investigation of P120catenin Expression in Human Basal Cell Carcinoma of the Skin
}

\author{
Vladimír Bartoš,*, Milada Kullová2
}

\begin{abstract}
Background: P120(ctn) is a specific membranous adhesion protein, that maintains the stability of intercellular junctions. An altered expression of 120 (ctn), either reduced in the cell membrane or increase in the cytoplasm, plays a crucial role in carcinogenesis. No research has analysed the expression of $\mathrm{p} 120$ (ctn) in basal cell carcinoma (BCC) of the skin so far. Therefore, we immunohistochemically studied p120(ctn) in a set of cutaneous BCCs in order to determine, whether there is difference in the expression pattern related to the histologic subtypes and tumor growth characteristics. Material and Methods: The study group consisted of 38 BCCs cathegorized into low-risk (non-infiltrative) subroup ( 8 superficial and 12 nodular subtypes) and high-risk (infiltrative) subgroup (10 nodular-infiltrative and 8 infiltrative subtypes). Specific monoclonal antibody against p120(ctn) was used for staining. Results: Overall, there were 12 cases (31.6\%) with normal preserved and 26 cases (68.4\%) with abnormal p120(ctn) expression. In superficial, nodular, nodular-infiltrative and infiltrative subtypes, abnormal p120(ctn) immunoreactivity was found in $37.5 \%$ (3/8), 41.7\% (5/12), 100\% (10/10) and 100\% (8/8), respectively. We have confirmed a strong correlation between the expression of p120(ctn) and both given, non-infiltrative and infiltrative BCC growth phenotypes. In the latter subgroup, almost all lesions showed diffusely reduced membranous staining, of which five also manifested an aberrant immunoreactivity in the cytoplasm. This cytoplasmic positivity occurred solely at the invasive front of the infiltrative tumor formations. Conclusion: Our results showed that decreased membranous expression of p120(ctn) was a frequent event in human cutaneous BCC and it was associated with infiltrative growth phenotype. Considering that nearly half of the BCCs with non-infiltrative growth pattern also exhibited reduced membranous expression, aberrant cytoplasmic immunoreactivity of p120(ctn), which was found exclusively in the high-risk BCC variants, can more reliably reflect and predict biological behaviour and malignant potential.
\end{abstract}

\section{KEYWORDS}

basal cell carcinoma; biological behaviour; P120catenin

\section{AUTHOR AFFILIATIONS \\ ${ }^{1}$ Department of Pathology, Faculty Hospital in Žilina, V. Spanyola 43, Žilina, 012 07, Slovakia \\ 2 Department of Dermatovenerology, Faculty Hospital in Žilina, V. Spanyola 43, Žilina, Slovakia \\ *Corresponding author: Björnsonova 3/5, Martin, 036 01; Slovakia; e-mail: vladim.bartos@gmail.com}

Received: 28 December 2016

Accepted: 23 March 2017

Published online: 7 June 2017

Acta Medica (Hradec Králové) 2017; 60(1): 32-36

https://doi.org/10.14712/18059694.2017.48

(c) 2017 The Authors. This is an open-access article distributed under the terms of the Creative Commons Attribution License (http://creativecommons.org/licenses/by/4.0), which permits unrestricted use, distribution, and reproduction in any medium, provided the original author and source are credited. 


\section{INTRODUCTION}

$\mathrm{P} 120$ catenin (p120(ctn)) is a specific cell-cell adhesion protein with multiple roles in different cellular compartments. It is funtionally linked to a wide variety of oncogenes and tumor suppressors, such as Src kinases, receptor tyrosine kinases and phosphatases, E-cadherin, $\beta$-catenin, RhoGTPases, Kaiso, and Wnt signaling effectors (1). A major role of p120(ctn) is to serve as a cadherin "gatekeeper". Under normal conditions, $\mathrm{p} 120$ (ctn) is expressed in the cell membrane and binds directly to the juxtamembrane domain of E-cadherin. This stabilizes cadherin and maintains the stability of intercellular adhesions (1). In contrast, when p120(ctn) is phosphorylated, it is dissociated from the cadherin tail, leading to cadherin internalization and consequently, the weakening of the cell-cell junctions. As a result, $\mathrm{p} 120$ (ctn) expression is reduced in the cell membrane and increased in the cytoplasm. Therefore, the subcellular distribution of p120(ctn) significantly modulate adhesion status of the cells and plays an important role in the carcinogenesis (1). There is accumulating evidence that altered expression of $\mathrm{p} 120$ (ctn) is related to tumor invasion and metastasis and its expression pattern correlates with cancer prognosis. Untill now, aberrant p120(ctn) expression has been reported as a potential prognostic indicator in many human malignancies, such as gastroesophageal adenocarcinoma (2), breast cancer (3), urinary bladder cancer (4), lung cancer (5), esophageal carcinoma (6), oral squamous cell carcinoma (7), colonic cancer (8), prostatic cancer (9), cholangiocellular carcinoma (10), hepatocellular carcinoma (11), and cutaneous squamous cell carcinoma (12). To the best of our knowledge, no research has analysed the expression of $\mathrm{p} 120$ (ctn) in basal cell carcinoma (BCC) of the skin despite the fact, it is currently the most common malignancy in humans. Therefore, the present study focused on the expression pattern of p120(ctn) in the series of cutaneous BCCs using immunohistochemistry. The main goal was to explain, whether there is difference in the expression patterns related to the histologic subtypes and tumor growth characteristics.

\section{MATERIAL AND METHODS}

\section{CLINICAL DATA AND TUMOR SPECIMENS}

Biopsy samples from 38 chosen cases of cutaneous BCCs from various topographic sites were enrolled into this study. They were obtained from 33 patients (13 males, 20 females) in the age range of 49-94 years (mean age 74.9 y.), who have been treated at the clinical departments of the Faculty Hospital in Žilina (Slovakia) and all biopsy specimens were histopathologically investigated at the Department of Pathology in Faculty Hospital in Žilina. For the purpose of this study, we selected a set of representative samples of cutaneous BCCs included four histomorphological subtypes: superficial (8 cases), nodular (12 cases), mixed nodular-infiltrative (10 cases), and infiltrative ( 8 cases). Further, according to the previous reports (13, 14) and recommendations proposed recently by The Royal College of Pathologists (15), they were divided into two separate subgroups for statistical analysis. The first sub- group comprised 20 low-risk (non-infiltrative) BCC subtypes (superficial and nodular). The second subgroup comprised 18 high-risk BCCs with (at least focal) infiltrative growth pattern (mixed nodular-infiltrative and infiltrative subtypes).

\section{IMMUNOHISTOCHEMISTRY}

Biopsy samples were routinely processed and immunohistochemical stained for calponin according to manufacturer's instructions. Shortly, representative $4-\mu \mathrm{m}$ tissue sections applied on silanized slides were baked for 2 hours in an oven at $56^{\circ} \mathrm{C}$. Then the sections were deparaffinized in xylene, rehydrated in series of descending ethanol concentrations and treated with microwaves in Dako Target Retrieval Solution (0.01 M citrate buffer, pH 6.0) for 20 minutes. The endogenous peroxidase activity was blocked with $3 \%$ hydrogen peroxide. Subsequently, specific monoclonal mouse antibody against p120 catenin (clone MRQ-5, DAKO, dilution 1:25) was used for staining. After incubation at ambient temperature, post primary antibody was applied and an immunoreaction was visualised by means of the DAB (3,3'-diaminobenzidine) detection chromogen solution. Slides were counterstained with Mayer's hematoxylin, dehydrated, mounted and finally evaluated in the light microscope. Positive reaction on epithelium of eccrine glands served as internal control.

DATA INTERPRETATION AND STATISTICAL ANALYSIS Based on the previous paper published by Wang et al. (5), we semiquantitatively classified tumors into 3 categories, according to the proportion of cancer cells that were immunoreactive for $\mathrm{p} 120$ (ctn). When $\geq 90 \%$ of the cancer cells stained in the cell membrane, the case was defined as normal membranous expression. When $<90 \%$ of the cancer cells stained for membranous expression, the case was defined as reduced membranous expression. Futher, when $\geq 10 \%$ of the cancer cells apparently stained within the cytoplasm, the case was defined as aberrant cytoplasmic expression. Both, reduced membranous and aberrant cytoplasmic expression (either alone or simultaneous within a single lesion) was considered abnormal. Data were collected in a databank, using a software SPSS Statistics. For the statistical analysis, chi-square test was employed and $\mathrm{P}$ value $<0.05$ was considered to indicate statistical significance.

\section{RESULTS}

In our series, p120(ctn) was expressed in 36 tumor samples with variable quantitative range and intensity. Two BCCs (one nodular and one nodular-infiltrative subtype) showed a completely negative staining. Overall, there were 12 cases $(31.6 \%)$ with normal preserved and 26 cases $(68.4 \%)$ with abnormal (including two lesions with negative) p120(ctn) expression. In the latter subgroup, almost all lesions showed diffusely reduced membranous staining, of which five (all of them comprising infiltrative growth pattern) also manifested an aberrant immunoreactivity in the cytoplasm. This cytoplasmic positivity was 
only focal, however, it occurred exclusively at the invasive front of tumor nests. No nuclear immunoreactivity was detected. Immunohistochemical status of p120(ctn) expression seemed to be related to histopathological BCC subtypes. In superficial, nodular, nodular-infiltrative and infiltrative subtypes, abnormal p120(ctn) immunoreactivity was found in $37.5 \%(3 / 8), 41.7 \%(5 / 12), 100 \%(10 / 10)$ and $100 \%(8 / 8)$, respectively. We have confirmed a strong correlation between the expression of $\mathrm{p} 120$ (ctn) and both given, low-risk and high-risk BCC subgroup $(\mathrm{p}=0.001)$. While non-infiltrative histologic subtypes of BCC manifested a normal preserved expression in the majority of the cases $(60 \%, 12 / 20)$ (Figure 1 and 2), all BCCs with infiltrative growth features $(100 \%, 18 / 18)$ showed abnormal type of p120(ctn) expression, including a strong cytoplasmic immunoreactivity (Figure 3 and 4). A summary of the immunohistochemical findings in our set of BCCs investigated is presented in Table 1.

Tab. 1: A summary of the immunohistochemical findings in the set of 38 BCCs we investigated (* including a case with completely negative staining).

\begin{tabular}{|c|c|c|c|}
\hline BCC subtype & $\mathbf{N}$ & Membranous expression of p120catenin & Aberrant cytoplasmic expression of p120catenin \\
\hline superficial & 8 & $\begin{array}{l}\text { normal } 5(62.5 \%) \\
\text { reduced } 3(37.5 \%)\end{array}$ & $\begin{array}{l}\text { no } 8(100 \%) \\
\text { present } 0(0 \%)\end{array}$ \\
\hline nodular & 12 & $\begin{array}{l}\text { normal } 7(58.3 \%) \\
\text { reduced } 5(41.7 \%)\end{array}$ & $\begin{array}{l}\text { no } 12(100 \%) \\
\text { present } 0(0 \%)\end{array}$ \\
\hline nodular-infiltrative & 10 & $\begin{array}{l}\text { normal } 0(0 \%) \\
\text { reduced* } 10(100 \%)\end{array}$ & $\begin{array}{l}\text { no } 8(80.0 \%) \\
\text { present } 2(20.0 \%)\end{array}$ \\
\hline infiltrative & 8 & $\begin{array}{l}\text { normal } 0(0 \%) \\
\text { reduced } 8(100 \%)\end{array}$ & $\begin{array}{l}\text { no } 5(62.5 \%) \\
\text { present } 3(37.5 \%)\end{array}$ \\
\hline
\end{tabular}

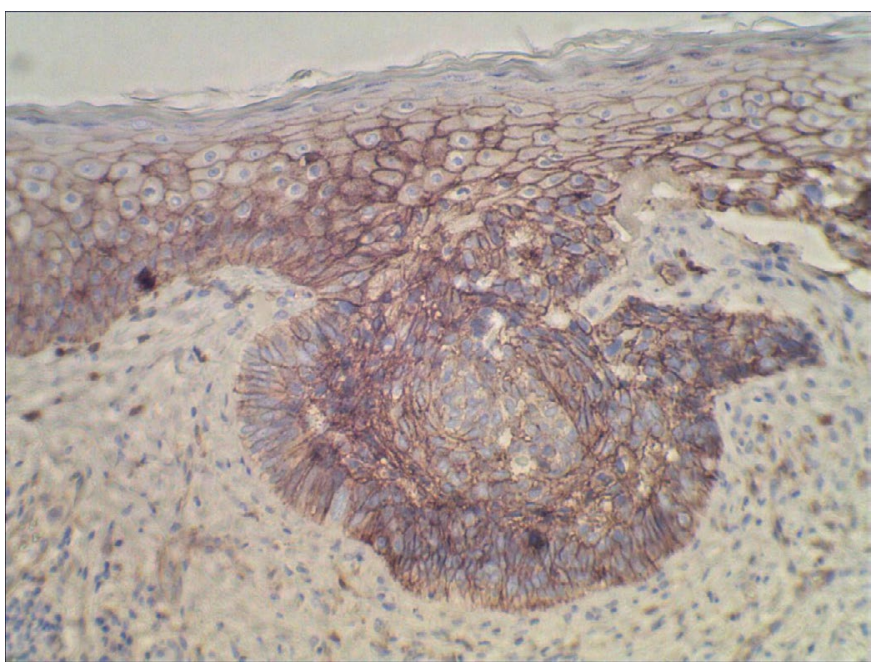

Fig. 1: Preserved diffuse membranous expression of p120(ctn) in superficial BCC (original magnification 200x).

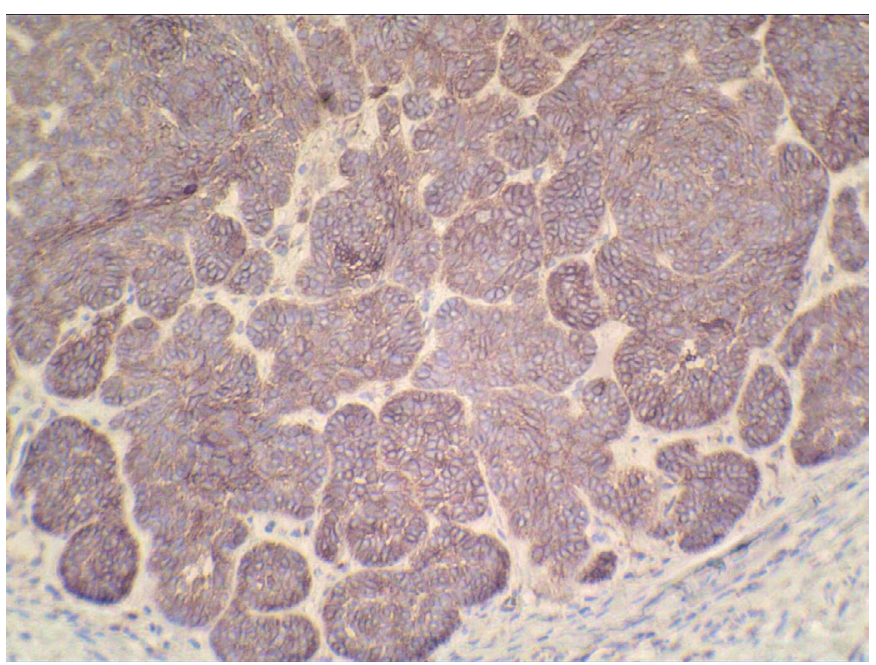

Fig. 2: Preserved diffuse membranous expression of p120(ctn) in nodular BCC (original magnification 100x).

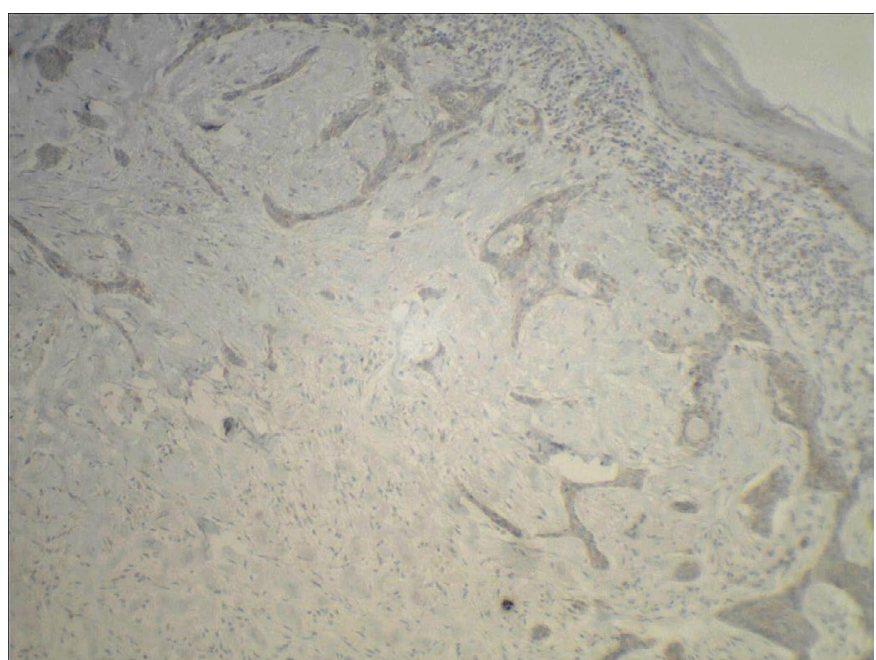

Fig. 3: Virtually completely absent expression of p120(ctn) in infiltrative BCC (original magnification 40x).

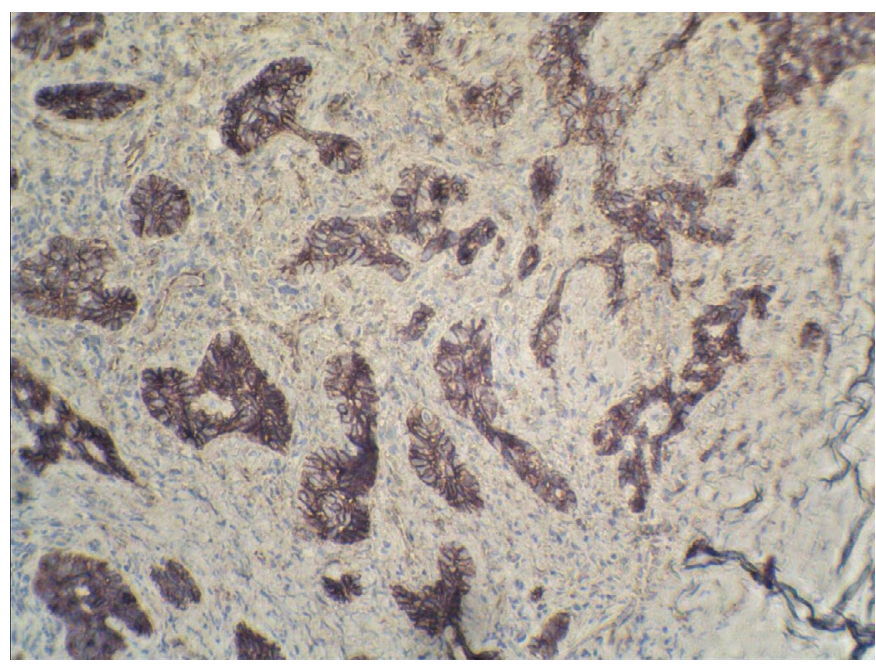

Fig. 4: Strong cytoplasmic expression of p120(ctn) within the tumor cells in infiltrative BCC. Some cells also show a concomitant immunoreactivity in the cell membrane (original magnification $200 \times)$. 


\section{DISCUSSION}

BCC of the skin is histomorphologically and phenotypically very heterogeneous oncological entity. It possess some unique features, such as slow local growth, strong stroma-dependency, and virtual absence of metastases $(16,17)$. Although it generally pursues a favourable clinical course, some cases show an aggressive behaviour, rapidly infiltrating deeper tissue structure and leading to treatment difficulties with local recurrences $(16,17)$. Many various molecular markers have been studied in cutaneous BCC until now (17), however, it is still not clearly understood, which of them are directly responsible for aggressive tumor behaviour and conversely, which potentially prevent cancer cells to metastasize.

This paper describes immunohistochemical expression status of cell-cell adhesion molecule p120(ctn) in a panel of 38 human BCCs of the skin. We have found that more than two thirds of the cases were accompanied by abnormal p120(ctn) expression. Therefore, a loss of normal membranous p120(ctn) expression is very frequent histopathological finding in cutaneous BCC. Of note, it has been found to be asssociated with infiltrative tumor growth. Our results are similar to those reported for other cancers $(2-12,18,19)$ which suggests that the decrease or loss of p120 (ctn) in the cell membrane plays a crucial role in tumorigenesis and a rising malignant potential. Interestingly, only a few cases concurrently exhibited an aberrant strong cytoplasmic immunoreactivity. This somewhat contradicts with many previous studies $(4,5,8,12,20-22)$ which have shown that the transition of $\mathrm{p} 120$ (ctn) from the cell membrane to the cytoplasm (or even into the nuclei) in various malignancies is associated with potentially invasive phenotype and disease progression and it might be more relevant prognostic indicator. In our study, among 26 BCCs with reduced or lost membranous immunostaining, only 5 lesions manifested apparent cytoplasmic accumulation of p120(ctn), which was not very extensive. Although this feature seemed to be link with infiltrative growth character of BCC, due to small number of such cases we did not evaluate a statistical significance. Since as far as we know, this is the first study addressing immunohistochemical investigation of $\mathrm{p} 120$ (ctn) in cutaneous BCC, we had no opportunity to compare our results with another observations. At this point, it seems likely that an invasive growth of BCC is accompanied by loss of membranous $\mathrm{p} 120$ (ctn) expression, however, usually without concomitant accumulation in the cytoplasm. This may be a special molecular feature of this human malignancy. A similar situation is known, for example, in the breast tumors, in which the lesions of ductal and lobular origin exhibit distinct expression patterns of p120(ctn). While the lobular neoplasms show a markedly increased cytoplasmic immunoreactivity without discernible cell membrane staining, ductal neoplasias show reduced membrane expression without appreciable cytoplasmic accumulation $(18,19)$.

In conclusion, our study showed that decreased membranous expression of $\mathrm{p} 120$ (ctn) was a frequent event in human cutaneous BCC and it was associated with infiltrative growth phenotype. Further, aberrant cytoplasmic immunoreactivity occurred only in a few cases, but it was found exclusively in the high-risk BCC variants at the invasive front of the infiltrative tumor formations. Considering that nearly half of the BCCs with non-infiltrative growth pattern also exhibited reduced membranous expression of p120(ctn), cytoplasmic positivity can more reliably reflect and predict biological behaviour and malignant potential. Further investigations are needed to elucidate the mechanism and role of $\mathrm{p} 120$ (ctn) in BCC biology and our present study may provide the basis for them.

\section{ACKNOWLEDGEMENTS}

The authors would like to thank Dr. Daniela Melova for her outstanding educational and technical assistance.

\section{REFERENCES}

1. Schackmann RC, Tenhagen M, van de Ven RA, Derksen PW. p120-catenin in cancer - mechanisms, models and opportunities for intervention. J Cell Sci 2013; 126: 3515-25.

2. Wijnhoven BP, Pignatelli M, Dinjens WN, Tilanus HW. Reduced p120ctn expression correlates with poor survival in patients with adenocarcinoma of the gastroesophageal junction. J Surg Oncol 2005; 92: 116-23.

3. Talvinen K, Tuikkala J, Nykänen $M$, et al. Altered expression of p120catenin predicts poor outcome in invasive breast cancer. Altered expression of 120 catenin predicts poor outcome in invasive breast cancer. J Cancer Res Clin Oncol 2010; 136: 1377-87.

4. Silva Neto B, Smith GL, Mandeville JA, et al. Prognostic significance of altered p120ctn expression in bladder cancer. BJU Int 2008; 101 : 746-52.

5. Wang EH, Liu Y, Xu HT, et al. Abnormal expression and clinicopathologic significance of p120-catenin in lung cancer. Histol Histopathol 2006; 21: 841-7.

6. Chen T, Wang C, Wu F, et al. Altered localization of p120 catenin in the cytoplasm rather than the membrane correlates with poor prognosis in esophageal squamous cell carcinoma. PloS One 2015; 10: e0118645. doi: 10.1371/journal.pone.0118645.

7. Jiang Y, Liao L, Shrestha C, et al. Reduced expression of E-cadherin and p120-catenin and elevated expression of PLC- $\gamma 1$ and PIKE are associated with aggressiveness of oral squamous cell carcinoma. Int J Clin Exp Pathol 2015; 8: 9042-51.

8. Bellovin DI, Bates RC, Muzikansky A, Rimm DL, Mercurio AM. Altered localization of p120 catenin during epithelial to mesenchymal transition of colon carcinoma is prognostic for aggressive disease. Cancer Res 2005; 65: 10938-45.

9. Van Oort IM, Tomita K, van Bokhoven A, et al. The prognostic value of E-cadherin and the cadherin-associated molecules alpha-, beta-, gamma-catenin and p120ctn in prostate cancer specific survival: a long-term follow-up study. Prostate 2007; 67: 1432-8.

10. Zhai B, Yan HX, Liu SQ, et al. Reduced expression of P120 catenin in cholangiocarcinoma correlated with tumor clinicopathologic parameters. World J Gastroenterol 2008a; 14: 3739-44.

11. Zhai B, Yan HX, Liu SQ, et al. Reduced expression of E-cadherin/catenins complex in hepatocellular carcinomas. World J Gastroenterol 2008b; 14: 5665-73.

12. Ishizaki Y, Omori Y, Momiyama M, et al. Reduced expression and aberrant localization of p120catenin in human squamous cell carcinoma of the skin. J Dermatol Sci 2004; 34: 99-108.

13. Nedved D, Tonkovic-Capin V, Hunt E, et al. Diagnostic concordance rates in the subtyping of basal cell carcinoma by different dermatopathologists. J Cutan Pathol 2014; 41: 9-13.

14. Bartoš V, Kullová M. Basal cell carcinoma of the skin with mixed histomorphology: a comparative study. Cesk Patol 2016; 52: 222-6.

15. Slater D, Walsh M. Standards and dataset for reporting cancers. Dataset for the histological reporting of primary cutaneous basal cell carcinoma. The Royal College of Pathologists. 3rd ed., May 2014. 29 pages.

16. Crowson AN. Basal cell carcinoma: biology, morphology and clinical implications. Mod. Pathol 2006; 19(Suppl 2): S127-S147.

17. Bartoš V, Adamicová K, Kullová M, Péč M. Basal cell carcinoma of the skin - biological hehaviour of the tumor and a review of the most important molecular predictors of disease progression in pathological practice. Klin Onkol 2011; 24: 8-17. (in Slovak) 
18. Dabbs DJ, Bhargava R, Chivukula M. Lobular versus ductal breast neoplasms: the diagnostic utility of p120 catenin. Am J Surg Pathol 2007; 31: 427-37.

19. Sarrió D, Pérez-Mies B, Hardisson D, et al. Cytoplasmic localization of p120ctn and E-cadherin loss characterize lobular breast carcinoma from preinvasive to metastatic lesions. Oncogene 2004; 23 : 3272-83.
20. Lo Muzio L, Pannone G, Staibano S, et al. p120(cat) Delocalization in cell lines of oral cancer. Oral Oncol 2002; 38: 64-72.

21. Mayerle J, Friess H, Büchler MW, et al. Up-regulation, nuclear import, and tumor growth stimulation of the adhesion protein $\mathrm{p} 120$ in pancreatic cancer. Gastroenterology 2003; 124: 949-60.

22. Shibata T, Kokubu A, Sekine S, Kanai Y, Hirohashi S. Cytoplasmic p120ctn regulates the invasive phenotypes of E-cadherin deficient breast cancer. Am J Pathol 2004; 164: 2269-78. 